\title{
Quality of attachment to father and mother and number of reciprocal friends
}

\author{
Manuela Veríssimo ${ }^{\mathrm{a} *}$, António J. Santos ${ }^{\mathrm{a}}$, Brian E. Vaughn ${ }^{\mathrm{b}}$, Nuno Torres ${ }^{\mathrm{a}}$, Ligia \\ Monteiro $^{\mathrm{b}}$ and Orlando Santos ${ }^{\mathrm{a}}$ \\ ${ }^{a}$ UIPCDE, Instituto Superior de Psicologia Aplicada, Rua Jardim do Tabaco, 34, 1100 Lisbon, \\ Portugal; ${ }^{b}$ Department of Human Development and Family Studies, Auburn University, \\ Auburn, AL, USA
}

(Received 23 June 2009; final version received 27 July 2009)

\begin{abstract}
Attachment research suggests that children with secure attachments are more able to construct meaningful relationships with peers. Few studies, however, have attempted to map early attachment security to the formation and maintenance of preschool friendships. Special attention has been paid to affiliative relationships (particularly friendships) because these are presumed to be of special importance with respect to a number of developmental outcomes and social adjustment indices. This study examined the relations between mother-child and father-child attachment relationships using the attachment Q-sort (AQS) and the number of reciprocated friendships of preschool children. Thirty-five mother-child and father-child dyads from bi-parental families participated in the study. Children were between 29 and 38 months of age for the first assessment. The organisation of children's secure base behaviour with both parents was assessed from separate observations of the child and parent at home. Subsequently, sociometric measures were used at four years of age to determine peer preferences. The correlation between the independent AQS scores for fathers and mothers was positive and significant $(r=.51, p<.05)$. Thus, there was consistency in child secure base behaviour across visits with each parent. Bivariate correlation and regression analyses showed a significant positive relation between AQS security with fathers (but not with mothers) and the number of reciprocated friendships $(r=.43$, $p<.05)$. Regression analyses indicated that AQS security with fathers remained a significant predictor of friendships even when AQS security with mothers was controlled. These findings may indicate a distinct relational effect of interaction quality with the father.
\end{abstract}

Keywords: mother attachment; father attachment; friendship; preschool

Bowlby (1982) recognised that secure base relationships might be constructed with any person who invests time and interest in the child on a regular basis and he suggested that fathers, familiar relatives and even non-related caregivers could be attachment figures (i.e. in addition to mothers), although he tended to view these attachments as secondary to the child's first and most salient attachment figure (usually the child's mother). Although attachment theory acknowledges that a child may have multiple attachments, the question of whether non-maternal caregivers, especially fathers, served as attachment figures occupied developmental researchers

*Corresponding author. Email: mveriss@ispa.pt 
for nearly a quarter century (e.g., Ahnert, Pinquart, \& Lamb, 2006; Bridges, Connell, \& Belsky, 1988; Caldera, 2004; Fox, Kimmerly, \& Schafer, 1991; Goossens \& van IJzendoorn, 1990; Howes \& Hamilton, 1992; Howes \& Oldham, 2001; Lamb, 1977, 1987; Main \& Weston, 1981; Rosen \& Burke, 1999; and Steele, Steele, \& Fonagy, 1996, provide reviews for non-parental and parental caregivers, respectively). These researches provided unequivocal evidence that non-maternal attachments are regular features of children's lives.

However, when fathers and children are studied, play interactions are often given greater emphasis, reflecting a stereotype concerning interaction domains preferred by fathers (e.g., Bowlby, 1982, 1989; Grossmann et al., 2002; Lamb \& Lewis, 2004). We note, however, that this stereotype is not necessarily instantiated in all cultures (e.g., Lamb, 1987). Irrespective of the interaction contexts studied most often for mothers or for fathers, most published reports have supported Bowlby's (1982) assumption that the child's transactions with a given caregiver supports the co-construction of an attachment relationship with that caregiver (e.g., Caldera, 2004; Grossman et al., 2002; Lamb, 1977; Main \& Weston, 1981; Monteiro, Veríssimo, Vaughn, Santos, \& Bost, 2008).

Interest in the father's role in child development, as well as his influence in the family context has increased significantly over the last 30 years as a consequence of the contemporary economic, social and cultural climate. In response to the changes in the economic climate, women have additional responsibilities in the broader economic sphere while continuing to accept (in large part) the responsibilities of homemaking and child care. Simultaneously, a new image of men as a caring father, who is actively engaged in the daily lives of his children and sharing household responsibilities and tasks in a more egalitarian way across economic, domestic and child-care spheres has been promoted (e.g., Balancho, 2004; Cabrera, Tamis-LeMonda, Bradley, Hofferth, \& Lamb, 2001; Deutsch, 2001; Lamb, Frodi, Hwang, \& Frodi, 1983; Parke, 1996). However, data suggest that, although some men are behaving differently from fathers in previous generations and perhaps differently from some of their peers, this "new father" does not necessarily conform to the image being conveyed by popular media (Lamb \& Tamis-Lemonda, 2004; Parke, 1996; Pleck \& Masciadrelli, 2004). This seems also to be true in Portugal, an EU country with one of the highest percentages of women in the labour force, particularly for those with preschool-age children (e.g., Amâncio \& Wall, 2004; Monteiro, Veríssimo, Castro, \& Oliveira, 2006; Torres, 2004). In a recent study of Portuguese families, both parents independently responded to a questionnaire about their participation in child related activities, relative to their spouse's participation in these activities. A traditional division in the Care/Organisation tasks and a shared participation in the Play/Leisure activities emerged (Monteiro et al., in press).

Fathers may have an impact on their children's development, both directly by means of interaction and indirectly by virtue of their impact (positive and negative) on the family's social and emotional climate (see Lamb, 2004). According to Bowlby (2002), fathers may act in support of the mother, both emotionally and instrumentally, which contributes to their children's healthy development. Goossens (1987) reported that when fathers' participation in care-giving and play activities, in dual-earner families, was characterised as more egalitarian, mothers felt more supported, and father participation was associated with child/mother attachment classifications in the strange situation (Ainsworth, Blehar, Waters, \& Wall, 1978). Also Monteiro et al. (in press) showed that fathers' participation in Play/Leisure activities was associated with the quality of secure base relationships within the family context. 


\section{Friendship}

In part due to mothers' increased labour force participation, most children are inserted into non-family settings with unfamiliar peers and adults and they begin the process of constructing a social network at younger and younger ages throughout the Western industrial world (as compared to the decades following WWII). A substantial number of studies have demonstrated that children as young as 24-30 months of age participate in complex networks of social relationships (e.g., Hay et al., 2004; Howes et al., 1998; Strayer \& Santos, 1996). Within these networks of social affiliations, interactions occur between familiarised peers and, over time, some of these peers become preferred interactive partners who are sought out when available. Gradually, these preferences become formalised as "friendships" (e.g., Howes, 1983). The establishment, maintenance and stability of positive friendship relations is believed to contribute to the development of social competence (Howes, 1983), more optimal adaptation to preschool and elementary school (Ladd \& Price, 1987; Rubin \& Coplan, 1998), as well as to psychological adjustment, well-being and social relations throughout life (e.g., SzewczykSokolowski, Bost, \& Wainwright, 2005).

Research suggests that peer interactions and especially friendships are fundamental to the socialisation of aggressive impulses, the development of social cognition, language skills and moral development, (e.g., Coie et al., 1992; Parker and Asher, 1987; Szewczyk-Sokolowski et al., 2005). As some authors point out, the influence of peers on children's behaviour can equal or sometimes exceed the influence of parents in areas such as play and aggression (Vaughn et al., 2000). On the other hand the presence of friends in a social group (e.g., classroom) increases the probability that the child can access social support when needed (Ladd and Kochenderfer, 1996). These benefits of friendships have prompted researchers to study the earliest peer contacts/ interactions and some (e.g., Hay et al., 2004) suggest that individual differences in number and quality of social relationships can be observed in infants and toddlers. These observations have prompted interest in the family relationships that may be potential antecedents to child friendships.

\section{Attachment and friendships}

Several studies of young children have shown a significant association between quality of attachment and both peer relations and number of reciprocated friendships (i.e., both children in a dyad choose each other as friends) (e.g., Clark \& Ladd, 2000; Schneider et al., 2001). In a meta-analysis based on 65 studies Schneider et al. (2001) verified the effect size of the association between attachment to mother and "success" in peer relations was $0.20(Z=11.91, p<0.001)$. For preschool children, Bost, Vaughn, Washington, Cielinsky, and Bradbard (1998) reported a significant association between quality of attachment and child social competence. For primary school children, Stams, Juffer, and van Ijzendoorn (2002) reported a similar association between attachment classification and measures of social competence. Especially, important for the present research is the study by Verschueren and Marcoen (1999) who found a significant association between secure attachment to father (but not with mother) and peer relationships. However, most "attachment to peer relationships" studies have focused on the relationship with mothers, whereas the role of father-child attachment as a support for the construction and maintenance of reciprocal friendships has been rarely studied. Only five (from 65) studies from the Schneider et al. (2001) meta-analysis considered the role of the father. Marcus and Mirle (1990) found that 
father attachment was related to boys' social competence and Rice, Cunningham, and Young (1997) also found that father attachment (but not mother-child attachment) in college students was related to social competence.

In this study, we tested longitudinally the relation between attachment security when the child is two to three years old (assessed in terms of the quality of secure base organisation with a specific parent) and the number of reciprocated friendships in the preschool classroom when the child is four years old. Given the inconsistencies in the literature regarding the possible predictive associations with father-child attachment, we independently assessed child attachment security with both mothers and fathers so as to be able to test for unique contributions of father-child attachment to the child's construction of reciprocated peer friendships in the preschool classroom.

\section{Method}

\section{Participants}

Thirty-five bi-parental families (one child from each family) participated in the study. The children attended two private daycare programmes in suburbs of Lisbon that were affiliated with a larger project on social development. When the attachment Q-sort (AQS) observations were completed, children were between 29 and 38 months of age $(M=31.91 ; \mathrm{SD}=2.56)$ and 20 were female. Two years after the initial contact, all children were interviewed in their childcare centres when they were approximately four to five years old. All families were European and both parents lived in the household. Age of entry into daycare ranged from four to 30 months $(M=8.67$; $\mathrm{SD}=6.59)$. The range of mothers' ages was $26-48$ years $(M=34.95$; $\mathrm{SD}=4.33)$ and fathers' ages ranged from 28 to 63 years $(M=37.48$; $\mathrm{SD}=6.08)$. Mothers' education level varied between seven and 23 years $(M=15.46 ; \mathrm{SD}=3.34)$ and fathers between seven and 23 years $(M=14.77$; $\mathrm{SD}=3.17)$. All families characterised themselves as "middle class", by the standards of the local community.

\section{Instruments}

Attachment Behaviour Q-Set (Waters, 1995, v. 3.0)

The AQS assesses the organisation of secure base behaviour in the presence of a major caregiver, in ecologically valid contexts (Vaughn \& Waters, 1990; Waters \& Deane, 1985). Secure base behaviour of the child is characterised in terms of its organisation in these contexts (Posada et al., 1995). The AQS provides a detailed description of the child's attachment behaviour and has been used to document both changes and continuities in the development of attachment relationships (Veríssimo, Blicharsky, Strayer, \& Santos, 1995). Furthermore, the AQS is particularly useful when multiple assessments are planned (as in our case because both mothers and fathers are assessed within a short period of time) because most children do not become negatively sensitised to the observers (as can happen when strange situation tests are repeated over a short time span) during the home observations (van IJzendoorn, Vereijken, Bakermans-Kranenburg, \& Riksen-Walraven, 2004; Waters \& Deane, 1985). Previous studies with Portuguese samples have demonstrated the utility and validity of the AQS in the Portuguese culture (Veríssimo, Monteiro, \& Santos, 2006; Veríssimo, Monteiro, Vaughn, Santos, \& Waters, 2005). 


\section{Sociometric measures}

A nominations sociometric task (McCandless \& Marshall, 1957) was administered individually by a trained research staff member. Children were presented with an array of photographs of their classmates and asked to identify a child they "especially liked". After making three such choices, the children were asked to identify a classmate they "did not especially like". They made three negative choices and then returned to the array to identify more "liked" children. The assistant requested choices until all class members' photographs were turned over.

Children were also interviewed with a paired-comparisons task. For this task, cards for all pairs of children in the class were prepared, with each child's photograph appearing on the left or right hand side of the stimulus cards an equal number of times. The order of presentation was such that no child was seen twice before all other children were seen once. Cards were presented one at a time and the child was asked, "Which of these two children do you especially like?" The number of pairs presented in this manner was substantial ( $n \times(n-1) / 2$, for 190 pairs in a class of 20 children) and some children grew tired of the task. If a child's attention appeared to wander, the assistant stopped the task and continued it later. All children included in this study completed the two tasks in one to three 15-minute sessions.

\section{Procedures}

\section{Home visits}

Mother-child and father-child dyads were observed during a home visit lasting between two and three hours. During visits with the father, the mother was asked not be present (and vice-versa). Home visits were counter-balanced (thus, for approximately half the families, fathers were observed first). The average interval between the visits was one month. The parents were told that the purpose of the visit was to better understand the child and the parent in their daily routine and experiences, for which reason they were asked to keep their daily activities unaltered as much as possible, in spite of the observers' presence. No other special restrictions were enforced during dyadic observations.

Two observers were present for all home visits and were never the same for the mother and father visit. The observers behaved as social visitors in the home, not intervening in family routines but participating in play if invited by the child. They talked informally with the parent but tried not to interfere with child-parent interactions. When it was opportune and in the sequence of the conversation with the parent, observers asked questions concerning Attachment Q-set items that could not be observed (e.g., Item 10 refers to the child's behaviour when he/she goes to bed) and about items they may not have observed during the visit (e.g., Item 45 refers to the child's liking to sing and dance to music).

Observers complete the AQS by distributing the 90 items into nine categories, according to a fixed distribution. After a sufficiently lengthy period of observation (a minimum of two hours), the observer sorts the items into categories that vary from "extremely characteristic" to "extremely uncharacteristic" for the observed child. Placement of an item in the distribution is determined by the salience/relevance of the item as observed (or reported by the caregiver) rather than by frequency or visibility per se (so, for example, determining that the child uses the mother as a base of exploration may take 60-90 minutes for a three- to five-year-old, but if observed, this item would be placed high in the distribution even though only a single cycle or two might 
be seen). Items that are more characteristic of the child are placed in the higher categories (9-7) and items least characteristic, or the ones that are not like the child are placed in the lower categories (1-3). Items that are neither characteristic nor uncharacteristic, or items that are not observed in the time frame of the observation are placed in the centre of the distribution (Categories 4-6). For scoring, the Q-description of the observed child is compared to a "criterion sort" described by Waters (1995). The criterion Q-sort was constructed by asking attachment experts to describe the "hypothetically most secure preschool child" using the AQS items, with the average item scores across experts serving as the final "criterion" for attachment security. Individual cases are evaluated in relation to this criterion by correlating the vector of item scores derived from the sort of an observed child with the vector of criterion item scores. This value indexes the similarity of the "observed child" to the idealised hypothetical child and ranges (in principle) from -1.0 to 1.0 . In practice, scores below -.25 or above .80 are rare.

\section{Sociometric interviews}

All children were interviewed when they were between four and five years old (two years after the AQS measures were collected). All children from the class (with parental consent) were interviewed using the two sociometric measures. Peer acceptance was scored as the number of positive choices received from peers. For purposes of identifying friendship pairs, a dyad was considered as being a reciprocated friendship dyad if both children named each other in the top $20 \%$ of choices on either the nominations or the paired comparisons sociometric tasks. When only one child made a positive friendship choice, the dyad was considered as a "non-reciprocated" friendship. Tests for relations between the total reciprocated friendships and both age and child gender were not significant.

\section{Results}

The AQS security scores with fathers ranged between -.04 and .79, with an average of $.41(\mathrm{SD}=0.20)$. Scores when children were seen with their mothers ranged between -.12 and .79 , with an average of $.43(\mathrm{SD}=0.21)$. These values are within the range of typical values identified by van IJzendoorn et al. (2004) in their meta-analysis of studies using the AQS in non-clinical samples. A repeated measures ANOVA grouped by child gender tested differences between the AQS scores for fathers vs. mothers. Neither main effects of parent (within subject), child gender, nor their interaction reached significance. These results are consistent with the literature on child attachments to both parents (e.g., Caldera, 2004; Frosch, Mangelsdorf, \& McHale, 2000; Main \& Weston, 1981).

The two AQS scores were themselves significantly correlated, $r(35)=.51, p<.01$. Thus, children with well-organised secure base behaviour with one parent tended also to show well-organised secure base behaviour with the other parent. This general finding is consistent with attachment results reported by Steele et al. (1996).

\section{Number of reciprocal friends}

Table 1 shows the correlations between AQS security scores for mother and father and the number of reciprocated and non-reciprocated friendships. Only the positive 
Table 1. Correlations between children's attachment quality and number of reciprocated and non-reciprocated friendships.

\begin{tabular}{lcc}
\hline & Reciprocated friendships & Non-reciprocated friendships \\
\hline AQS security mother & 0.31 & -0.21 \\
AQS security father & $0.43^{*}$ & -0.22 \\
\hline
\end{tabular}

$* p<.05$.

Table 2. Hierarchical regression analysis predicting children's reciprocal friendships from attachment quality with father and mother.

\begin{tabular}{lcccc}
\hline & $R$ & $R^{2}$ & $\Delta R^{2}$ & $\beta$ \\
\hline Step 1 & 0.48 & 0.23 & & $0.48^{*}$ \\
Father AQS & & & 0.00 & $0.44^{*}$ \\
Step 2 & 0.48 & 0.23 & & 0.06 \\
Father AQS & & & & \\
Mother AQS & & & &
\end{tabular}

correlation between attachment security with fathers and the number of reciprocal friendships reached significance, although a trend in the same direction was found for security with mother. To determine whether father AQS scores or mother AQS scores uniquely predicted number of reciprocal friends, a hierarchical multiple regression was computed. Father AQS scores were entered at the first step with the maternal AQS score entered at the second step. Results are presented in Table 2. The first step of the regression reproduces the zero-order correlation between father-child attachment and reciprocated friendships and is significant. The AQS security score with mother was added at the second step. As shown in Table 2 , the overall $\mathrm{R}^{2}$ did not change when the AQS score with mother was added and the $\beta$ weight for the father score remained significant. These results suggest that it was the child's attachment security with father, rather than with mother, that predicted children's reciprocated friendships in this sample.

\section{Discussion}

Our first results indicate there is some significant consistency across parents with regard to the organisation of child secure base behaviour. Thus, not only can we say that the child is attached to both parents, but the nature of his/her attachment is similar for both parents. On average, both parents were treated by the child as a "secure base for exploration and haven of safety in time of need", which was suggested by Ainsworth et al. (1978) as the fundamental indicator of the presence of an attachment relationship. Our results are in agreement with previous studies showing similarity across parents with respect to attachment (Monteiro et al., 2008; Steele et al., 1996). However, even though the quality of attachment to mother and father is similar, security may be associated with different developmental outcomes. 
In this study, children secure with fathers tend to have more reciprocal friends, a result that may indicate the existence of a distinct relational effect of the father-child attachment. The presence of different styles of interaction and play shown by mothers and fathers since the first months of life (for example, fathers are more unpredictable and more physically stimulating in play, while mothers are more tranquil and object mediated) may have a different impact in developmental trajectories. Grossman et al. (2002) showed that father sensitivity in exploration play during infancy was a good predictor of secure internal models at 10 years of age. Our results are also similar to the study by Vershueren and Marcoen (2005), where a similar relation between attachment to father and number of friendships was found. Father interaction style may have a double effect of promoting secure relations and better abilities in dealing with peers. Children may learn from fathers how to deal with more aggressive behaviours and how to regulate their friendship relations. A secure attachment to father may help the child to better understand how to develop friendship relations in more and more complex social networks.

Steele et al. (1996) suggested that attachment to mothers is more related with the internal world of the child while attachment to fathers is more related to the external world. The concepts of friendship of preschool children tend to emphasise social proximity, and common interests in activities and games (e.g., Berndt, 2002), in other words, it focuses on the external world. When the child reaches school age and especially in adolescence friendship is more related to psychological characteristics and particularly to the development of intimacy (Youniss, 1986). Intimacy implies exclusive focus, openness of self-disclosure and sharing of problems and advice between friends and it is probably more related to qualities of the inner world. What we would like to suggest is that quality of attachment to fathers and mothers may play different roles in the construction of friendships, depending on the child's level of maturity. Thus, fathers may guide the child's entrance into the larger social world of peers and provide support for the initial construction of friendships, while the relationship quality with mothers may be the key for supporting deeper, more psychologically encompassing friendships during adolescence.

One of the limitations of the present work is the lack of data on quality of friendship. Previous research suggests that having friends has generally positive implications for social adjustment and mental health (see Hartup, 1996), but there is also an emerging awareness that the quality of specific friendships may vary across a wide range of values (Berndt, 1996; Howes, 1983). Furthermore, when friends endorse and support behaviour that undermines physical and/or mental health, the probability of negative consequences increases (e.g., Cairns \& Cairns, 1994; Dishion, Eddy, Haas, Li, \& Spracklen, 1997). The recent focus on quality and diversity of friendships and on the fact that the consequences of friendship are not always benign suggests that there is much left to learn about how, when and why friendships exert influences on the development of individual children. Bukowski, Pizzamiglio, and Newcomb (1996) commented that exploration of diversity and effects of differences in qualities of friendships requires rather more complex research designs than have been common so far, including coordination of multiple relationships, longitudinal assessments and experiments to test for specific outcomes contingent on friendship quality. Future work should not only include data on quality of friendship but also analyse possible differences in the results depending on gender. It would be important to verify if the association between quality of attachment to parents and number of reciprocal friends is different in function of the child gender. 


\section{Acknowledgements}

This study was supported in part by FCT Grants PTDC/PSI/64149/2006, PTDC/PSI/66172/ 2006 and NSF BCS 0623019. The authors would like to thank all the parents and children who participated in this study. The authors would also like to thank all the members of Line 1, UIPCDE, for their help in data collection and insightful comments.

\section{Notes on contributors}

Manuela Veríssimo is a professor at the Instituto Superior de Psicologia Aplicada, Lisboa, Portugal.

António J. Santos is a professor at the Instituto Superior de Psicologia Aplicada, Lisboa, Portugal.

Brian E. Vaughn, is a professor in Human Development and Family Studies, Auburn University, USA.

Nuno Torres is a post doc at the Instituto Superior de Psicologia Aplicada, Lisboa, Portugal.

Ligia Monteiro is a post doc in Human Development and Family Studies, Auburn University, USA.

Orlando Santos is a doctoral student at the Instituto Superior de Psicologia Aplicada, Lisboa, Portugal.

\section{References}

Ahnert, L., Pinquart, M., \& Lamb, M.E. (2006). Security of children's relationships with nonparental care providers: A meta-analysis. Child Development, 74, 664-679.

Ainsworth, M.D.S., Blehar, M.C., Waters, E., \& Wall, S. (1978). Patterns of attachment: A psychological study of the strange situation. Hillsdale, NJ: Erlbaum.

Amâncio, L., \& Wall, K. (2004). Famílias e papeis de género: Alguns dados recentes do Family and Gender Survey (ISSP)[Families and gender roles: Some recent data from the Family and Gender Survey]. Coimbra, Portugal: VIII Congresso Luso-Afro-Brasileiro de ciências sociais.

Balancho, L.S. (2004). Ser pai: Transformações intergeracionais na paternidade. (Being a father: Intergenerational transformations in parenthood) Análise Psicológica, 22(2), 377-386.

Berndt, T.J. (1996). Exploring the effects of friendship quality on social development. In W.M. Bukowski, A.F. Newcomb, \& W.W. Hartup (Eds.), The company they keep: Friendship in childhood and adolescence (pp. 346-365). Cambridge: Cambridge University Press.

Berndt, T.J. (2002). Friendship quality and social development. Current Directions on Psychological Science, 11, 7-11.

Bost, K.K., Vaughn, B.E., Washington, W.N., Cielinsky, K.L., \& Bradbard, M.R. (1998). Social competence, social support, and attachment: Demarcation of construct domains, measurement, and paths of influence for preschool children attending head start. Development Child, 69(1), 192-218.

Bowlby, J. (1982). Attachment and loss: Attachment (Vol.1, 2nd Rev. ed.). New York: Basic Books (Original work published 1969).

Bowlby, J. (1989). The role of attachment in personality development and psychopathology. In S. Greenspan \& G. Pollack (Eds.), The course of life: Infancy (Vol. 1, pp. 229-270). Madison, CT: International University Press.

Bowlby, J. (2002). Cuidados maternos e saúde mental (4⿳亠丷⿵冂丶 ed.) [Maternal care and mental health]. São Paulo: Martins Fontes.

Bridges, L.J., Connel, J.P., \& Belsky, J. (1988). Similarities and differences in infant-mother and infant-father interaction in the estrange situation: A component process analysis. Developmental Psychology, 24(1), 92-100. 
Bukowski, W.M., Pizzamiglio, M.T., \& Newcomb, A.F. (1996). Popularity as an affordance for friendship: The link between group and dyadic experience. Social Development, 5(2), 189-202.

Cabrera, N.J., Tamis-LeMonda, C.S., Bradley, R.H., Hofferth, S., \& Lamb, M. (2001). Fatherhood in the twenty-first century. Child Development, 71(1), 127-136.

Cairns, R.B., \& Cairns, B.D. (1994). Lifeline and risks: Pathways of youth in our time. New York: Cambridge University Press.

Caldera, Y.M. (2004). Paternal involvement and infant-father attachment: A Q-set study. Fathering, 2(2), 191-210.

Clark, K.E., \& Ladd, G.W. (2000). Connectedness and autonomy support in parent-child relationships: Links to children's socioemotional orientation and peer relationships. Developmental Psychology, 36(4), 485-498.

Coie, J.D., Lochman, J.E., Terry, R., \& Hyman, C. (1992). Predicting early adolescent disorder from childhood aggression and peer rejection. Journal of Consulting and Clinical Psychology, 60, 783-792.

Deutsch, F.M. (2001). Equally shared parenting. American Psychological Society, 10(1), 25-28.

Dishion, T.J., Eddy, J.M., Haas, E., Li, F., \& Spracklen, K. (1997). Friendships and violent behavior during adolescence. Social Development, 6, 207-223.

Fox, N., Kimmerly, N., \& Schafer, W. (1991). Attachment to mother/attachment to father: A meta-analysis. Child development, 62, 210-225.

Frosch, C., Mangelsdorf, S.C., \& McHale, J.L. (2000). Marital behavior and the security of preschooler parent-parent attachment relationships. Journal of Family Psychology, 14(1), 144-161.

Goossens, F. (1987). Maternal employment and day care. Efects on attachment. In L.W.C. Tavecchio \& M.H.Van IJzendoorn (Eds.), Attachment in social networks. Amsterdam, The netherlands: Elsevier.

Goossens, F.A., \& van IJzendoorn, M.H. (1990). Quality of infants' attachments to professional caregivers: Relation to infant-parent attachment and day-care characteristics. Child Development, 61, 832-837.

Grossmann, K., Grossmann, K., Fremmer-Bombik, E., Kindler, H., Scheuerer-Englisch, H., \& Zimmermann, P. (2002). The uniqueness of the child-father attachment relationship: Father's sensitive and challenging play as a pivotal variable in a 16-year longitudinal study. Social development, 11(3), 307-331.

Hartup, W.W. (1996). The company they keep: Friendships and their developmental significance. Child Development, 67, 1-13.

Hay, D.F., Payne, A., \& Chadwick, A. (2004). Peer relations in childhood. Journal of Child Psychology and Psychiatry, and Allied Disciplines, 45, 84-108.

Howes, C. (1983). Patterns of friendship. Child Development, 54(4), 1041-1053.

Howes, C., \& Hamilton, C.E. (1992). Children's relationships with caregivers: Mothers and child care teachers. Child Development, 63(4), 859-866.

Howes, C., \& Oldham, E. (2001). Processes in the formation of attachment relationships with alternative caregivers. In A. Goncu \& E. Klein (Eds.), Children in play, story and school (pp. 267-287). New York: Greenwood.

Howes, C., Hamilton, C.E., \& Phillipsen, L.C. (1998). Stability and continuity of childcaregiver and child-peer relationships. Child Development, 69(2), 418-426.

Ladd, G.W., \& Kochenderfer, B.J. (1996). Linkages between friendship and adjustment during early school transitions. In W.M. Bukowski, A.F. Newcomb, \& W.W. Hartup (Eds.), The company they keep: Friendship in childhood and adolescence (pp. 322-345). New York: Cambridge University Press.

Ladd, G., \& Price, J.M. (1987). Predicting children's social and school adjustment following the transition from preschool to kindergarten. Child Development, 58(5), 1168-1180.

Lamb, M. (1977). Father-infant and mother-infant interactions in the first year of life. Child Development, 48, 167-181.

Lamb, M. (1987). Introduction: The emergent American father. In M. Lamb (Ed.), The father's role: Cross-cultural perspectives (pp. 3-26). New Jersey: Lawrence Erlbaum.

Lamb, M., Frodi, M., Hwang, C., \& Frodi, A. (1983). Effects of paternal involvement for mothers and fathers. Child Development, 54, 450-458. 
Lamb, M.E. (Ed.). (2004). The role of the father in child development. Hoboken, NJ: John Wiley.

Lamb, M.E., \& Lewis, C. (2004). The development and significance of father-child relationships in two-parent families. In M.E. Lamb (Ed.), The role of the father in child development (pp. 272-306). Hoboken, NJ: John Wiley.

Lamb, M.E., \& Tamis-Lemonda, C.S. (2004). The role of the father: An introduction. In M.E. Lamb (Ed.), The role of the father in child development (pp. 1-31). Hoboken, NJ: John Wiley.

Main, M., \& Weston, D.R. (1981). The quality of the toddler's relationship to mother and to father: Related to conflict behavior and the readiness to establish new relationships. Child Development, 52, 932-940.

Marcus, R.F., \& Mirle, J. (1990). Validity of a child interview measure of attachment as used in child custody evaluations. Perceptual and Motor Skills, 70, 1043-1054.

McCandless, B.R., \& Marshall, H.R. (1957). A picture sociometric technique for preschool children and its relation to teacher judgments of friendship. Child Development, 28, 139-148.

Monteiro, L., Veríssimo, M., Castro, R., \& Oliveira, C. (2006). Partilha da responsabilidade parental: Realidade ou expectativa? [Sharing parental responsibility: Reality or expectations?]. Psychologica, 42, 213-229.

Monteiro, L., Verissimo, M., Vaughn, B.E., Santos, A.J., \& Bost, K.K. (2008). Secure base representations for both fathers and mothers predict children's secure base behavior in a sample of Portuguese families. Attachment \& Human Development, 10(2), 1-18.

Monteiro, L., Veríssimo, M., Vaughn, B.E., Santos, A.J., Torres, N., \& Fernandes, M. (in press). The organization of children's secure base behaviour in two parent Portuguese families and father's participation in child related activities. European Journal of Developmental Psychology.

Parke, R.D. (1996). Fatherhood. The developing child (J. Bruner, M. Cole, \& A. KarmiloffSmith, Series Eds.). Cambridge, MA: Harvard University Press.

Parker, J.G., \& Asher, S.R. (1987). Peer relations and later personal adjustment: Are lowaccepted children at risk? Psychological Bulletin, 102(3), 357-389.

Pleck, J.H., \& Masciadrelli, B.P. (2004). Paternal involvement by U.S. residential fathers. Levels, sources, and consequences. In M.E. Lamb (Ed.), The role of the father in child development (pp. 222-306). Hoboken, NJ: John Wiley.

Posada, G., Goa, Y., Wu, F., Posada, R., Tascon, M., Schoelmerich, A., et al. (1995). The secure-base phenomenon across cultures: Children's behavior, mother's preferences and experts concepts. In E. Waters, B.E., Vaughn, G., Posada \& K. Kondo-Ikemura (Eds.), Monographs of the Society for Research in the Child Development, 60(2-3), 27-47.

Rice, K.G., Cunningham, T.J., \& Young, M. (1997). Attachment, social competence, and emotional wellbeing: A comparison of black and white late adolescents. Journal of Counseling Psychology, 44, 89-101.

Rosen, K.S., \& Burke, P.B. (1999). Multiple attachment relationships within families: Mothers and fathers with two young children. Developmental Psychology, 35(2), 436-444.

Rubin, K.H., \& Coplan, R.J. (1998). Social and non-social play in early childhood: An individual differences perspective. In O.N. Saracho \& B. Spodeck (Eds.), Multiple perspectives on play in early childhood education (pp. 144-170). Albany, NY: SUNY Press.

Schneider, B.H., Atkinson, L., \& Tardif, C. (2001). Child-parent attachment and children's peer relations: A quantitative review. Developmental Psychology, 37, 86-100.

Stams, G.J.J.M., Juffer, F., \& van IJzendoorn, M.H. (2002). Maternal sensitivity, infant attachment, and temperament in early childhood predict adjustment in middle childhood: The case of adopted children and their biologically unrelated parents. Developmental Psychology, 38, 806-821.

Steele, H., Steele, M., \& Fonagy, P. (1996). Associations among attachments classifications of mothers, fathers and their infants. Child Development, 67, 541-555.

Strayer, F.F., \& Santos, A.J. (1996). Affiliative structures in preschool peer groups. Social Development, 5(2), 117-130.

Szewczyk-Sokolowski, M., Bost, K., \& Wainwright, A. (2005). Attachment, temperament and preschool children's peer acceptance. Social Development, 14(3), 379-397.

Torres, A. (2004). Vida conjugal e o trabalho. Uma perspective sociológica [Marital life and work: A sociological perspective]. Oeiras: Celta. 
van IJzendoorn, M.H., Vereijken, C.M.J.L., Bakermans-Kranenburg, M.J., \& RiksenWalraven, J.M. (2004). Assessing attachment security with the attachment Q-sort: Metaanalytic evidence for the validity of the observer AQS. Child Development, 75, 1188-1213.

Vaughn, B.E., Azria, M.R., Krzysik, L., Caya, L.R., Bost, K.K., Newell, W., et al. (2000). Friendship and social competence in a sample of preschool children attending head start. Development Psychology, 36(3), 326-338.

Vaughn, B.E., \& Waters, E. (1990). Attachment behavior at home and in the laboratory: Q-sort observations and strange situation classifications of one-year-olds. Child Development, 61, 1965-1973.

Veríssimo, M., Blicharsky, T., Strayer, F., \& Santos, A. (1995). Vinculação e estilos de comunicação da criança [Attachment and communication styles in childhood]. Análise Psicológica, 1-2(XIII), 145-155.

Veríssimo, M., Monteiro, L., \& Santos, A.J. (2006). Para além da mãe: Vinculação na tríade mãe-pai-criança [Beyond the mother: Attachment in the mother-father-child triad]. In J.C. Coelho Rosa \& S. Sousa (Eds.), Caderno do bebé (pp. 73-85). Lisboa: Fim de Século.

Veríssimo, M., Monteiro, L, Vaughn, B.E., Santos, A.J., \& Waters, H. (2005). Coordenação entre o modelo interno dinâmico da mãe e o comportamento de base-segura dos seus filhos [The coordination between mothers internal working model and child secure base behaviour]. Análise Psicológica, XXIII(2), 7-17.

Verschueren, K., \& Marcoen, A. (1999). Representation of self and socioemotional competence in kindergartners: Differential and combined effects of attachment to mother and to father. Child Development, 70(1), 183-201.

Verschueren, K., \& Marcoen, A. (2005). Perceived security of attachment to mother and father: Developmental differences and relations to self-worth and peer relationships at school. In K. Kerns \& R. Richardson (Eds.), Attachment in middle childhood (pp. 212230). New York: Guilford Press.

Waters, E. (1995). Appendix A: Attachment Q-set (version 3.0). In E. Waters, B.E. Vaughn, G. Posada \& K. Kondo-Ikemura (Eds.), Monographs child development, 60(2-3), 234-246.

Waters, E., \& Deane, K. (1985). Defining and assessing individual differences in attachment relationships: Q-methodology and the organization of behavior in infancy and early childhood. In I. Bretherton \& E. Waters (Eds.), Monographs of the society for research in the child development, 50(1-2), 41-65.

Youniss, J. (1986). Development in reciprocity through friendship. In C. Zahn-Waxler, E.M. Cummings, \& R. Iannotti (Eds.), Altruism and aggression: Biological and social origins (pp. 88-106). Cambridge: Cambridge University Press. 
Copyright of Early Child Development \& Care is the property of Routledge and its content may not be copied or emailed to multiple sites or posted to a listserv without the copyright holder's express written permission. However, users may print, download, or email articles for individual use. 